\title{
Complex Function by Design Using Spatially Pre-Structured Synthetic Microbial Communities: Degradation of Pentachlorophenol in the Presence of $\mathrm{Hg}(\mathrm{II})^{\dagger}$
}

\author{
Hyun Jung Kim, Wenbin Du, and Rustem F. Ismagilov \\ Department of Chemistry and Institute for Biophysical Dynamics, The University of Chicago, 929 \\ East 57th Street, Chicago, Illinois 60637
}

\begin{abstract}
Naturally occurring microbes perform a variety of useful functions, with more complex processes requiring multiple functions performed by communities of multiple microbes. Synthetic biology via genetic engineering may be used to achieve desired multiple functions, e.g. multistep chemical and biological transformations, by adding genes to a single organism, but this is sometimes not possible due to incompatible metabolic requirements or not desirable in certain applications, especially in medical or environmental applications. Achieving multiple functions by mixing microbes that have not evolved to function together may not work due to competition of microbes, or lack of interactions among microbes. In nature, microbial communities are commonly spatially structured. Here, we tested whether spatial structure can be used to create a community of microbes that can perform a function they do not perform individually or when simply mixed. We constructed a core-shell fiber with Sphingobium chlorophenolicum, a pentachlorophenol (PCP) degrader, in the core layer and Ralstonia metallidurans, a mercuric ion $(\mathrm{Hg}(\mathrm{II}))$ reducer, in the shell layer as a structured community using microfluidic laminar flow techniques. We applied a mixture of PCP and $\mathrm{Hg}(\mathrm{II})$ to either a simple well-mixed culture broth (i.e. the unstructured community) or the spatially structured core-shell fibers. We found that without spatial structure, the community was unable to degrade $\mathrm{PCP}$ in the presence of $\mathrm{Hg}$ (II) because S. chlorophenolicum is sensitive to $\mathrm{Hg}(\mathrm{II})$. In contrast, with spatial structure in a core-shell fiber system, $S$.

chlorophenolicum in a core layer was protected by $R$. metallidurans deposited in a shell layer, and the community was able to completely remove both PCP and $\mathrm{Hg}$ (II) from a mixture. The appropriate size of the core-shell fiber was determined by the Damköhler number-the timescale of removal of $\mathrm{Hg}$ (II) was on the same order of the timescale of diffusion of $\mathrm{Hg}$ (II) through the outer layer when the shell layer was on the order of $\sim 200 \mu \mathrm{m}$. Ultimately, with the ease of a child putting together 'Legos' to build a complex structure, using this approach one may be able to put together microorganisms to build communities that perform functions in vitro or even in vivo, e.g. as in a "microbiome on a pill".
\end{abstract}

\section{Introduction}

This paper describes an approach to synthetic biology that does not require genetic engineering to create complex functions: instead of combining genes in an organism, we used microfluidics to combine organisms within a spatially structured microbial community. The solutions to many societal problems, such as combating disease, remediating

\footnotetext{
$\dagger$ Electronic Supplementary Information (ESI) available: supporting figures. See DOI: 10.1039/b000000x/

This journal is @ The Royal Society of Chemistry [year]

Correspondence to: Rustem F. Ismagilov.
} 
environmental contaminants, and producing food and fuels, require multiple functions to be performed. Synthetic biology attempts to address these problems by constructing biological systems to carry out the desired functions ${ }^{1-5}$ or to investigate spatial dynamics of interacting microbial communities, ${ }^{6,7}$ and microbes are often used to this end. One approach to synthetic biology is to genetically engineer microbes, so that all the desired functions are carried out by a single strain. ${ }^{8,9}$ However, multiple functions can be difficult to combine into a single organism, as these functions may require contrasting metabolic pathways or mutually exclusive environments such as aerobic vs. anaerobic. Genetic engineering is not straightforward if the genetics of the organism and the genes involved are not fully known. Also, it may be difficult to justify the use of genetically modified organisms outside of bioreactors, especially in environmental or medical applications. Another potential approach to synthetic biology is to engineer a microbial community to perform the desired functions. Often this is done by simply mixing several species of microbes, as is commonly done for probiotics ${ }^{10}$ bioremediation, ${ }^{11}$ or biofuel production, ${ }^{12}$ but a multispecies community may not be stable or viable if the species have differential growth rates or mismatched nutritional gradients, or if toxic compounds are released by one species. ${ }^{7,13-17}$ Microbial communities are common in nature and can perform multiple functions that a single organism cannot perform. More importantly, many of these communities have specific spatial structures (Figure 1). ${ }^{18}$ Although these structured communities are common, how spatial structure impacts the function of these communities is only beginning to be understood. ${ }^{7,19,20}$ Mimicking these spatially structured communities in the laboratory could provide additional understanding of how spatial structure modulates microbial interactions.

Here we tested whether spatial structure can be used to create a biomimetic synthetic community of microbes to perform a function they do not perform individually or when simply mixed. We tested this hypothesis by using a community we designed to remove a mixture of pollutants: pentachlorophenol (PCP) and the heavy metal ion $\mathrm{Hg}$ (II). These two contaminants are likely to co-exist at sites where PCP was produced by direct chlorination with chlorine that was obtained by electrolysis using $\mathrm{Hg}$ electrodes in a chloralkali process. ${ }^{21-} 25$ Heavy metals inhibit the degradation of organic pollutants, making simultaneous degradation difficult.26-28 PCP is one of the most recalcitrant and toxic environmental pollutants, ${ }^{28-31}$ and the levels of PCP found in soil are as high as $200 \mathrm{mg} / \mathrm{kg}$-soil. ${ }^{32}$ Mercury is highly toxic to bacteria, ${ }^{33}$ and the levels of mercury found in contaminated soil range from 0.01 to $4.6 \mathrm{mg} / \mathrm{kg}$-soil in US. ${ }^{34}$ Rather than expressing multiple genes in a single organism to perform multiple functions, we used microfluidics to construct a synthetic functional community where a species that was sensitive to one pollutant was protected by another species. Sphingobium chlorophenolicum (ATCC 53874) is an aerobic, pH-neutral (Figure S1) PCP degrader ${ }^{33}$ that is sensitive to mercury and is unable to remove $\mathrm{Hg}$ (II) ions (Figure S2). We protected the mercury-sensitive $S$. chlorophenolicum by surrounding it with the mercury-reducing Ralstonia metallidurans (ATCC 43123$)^{35,36}$ that does not decompose PCP (Figure S3). We used a microfluidic device (Figure 2) to construct a functional community within a core-shell structure in a Ca-alginate gel fiber, and tested whether spatial structure enables the community to decompose PCP and reduce $\mathrm{Hg}$ (II) simultaneously when we applied the complex contaminant mixture in the reaction medium.

\section{Results and Discussion}

First, to test the importance of spatial structure, we tested whether the community could degrade the mixture of pollutants in the absence of spatial structure by measuring the rate of removal of a mixture of both PCP and $\mathrm{Hg}$ (II) (Figure 3a). Concentrations of mercury were measured using cold vapor atomic absorption analysis; concentrations of PCP were determined by HPLC analysis ${ }^{37}$ (see Experimental section). The degradation of PCP to tetrachloro- $p$-hydroquinone (Figure 2a) is the rate limiting step when PCP is decomposed 
aerobically, followed by dechlororination steps and a ring fission step. ${ }^{37}$ While $\mathrm{Hg}$ (II) ions were rapidly reduced by the well-mixed, unstructured community, degradation of PCP by this community was negligible (Figure 3a). Control experiments showed that this lack of degradation of PCP was not due to the presence of $R$. metallidurans, as $R$. metallidurans does not interfere with PCP degradation by $S$. chlorophenolicum in a well-mixed community (Figure 4). Furthermore, PCP was not toxic to these strains at the concentrations used (Figure S4). However, $\mathrm{Hg}$ (II) ions were toxic to S. chlorophenolicum at $50 \mu \mathrm{M}$ (Figure S5) and $20 \mu \mathrm{M}$ (Figure S6), suggesting that the lack of degradation of PCP by the unstructured community was due to the expected sensitivity of $S$. chlorophenolicum to $\mathrm{Hg}$ (II) ions.

We hypothesized that a core-shell spatial structure (Figure 2a), with $S$. chlorophenolicum in the core and $R$. metallidurans in the shell, would result in a community that is able to both remove $\mathrm{Hg}(\mathrm{II})$ ions and degrade $\mathrm{PCP}$. The $S$. chlorophenolicum cells in the core would degrade the PCP and be protected from the $\mathrm{Hg}$ (II) ions by the $R$. metallidurans cells in the shell, which would reduce the $\mathrm{Hg}(\mathrm{II})$ to $\mathrm{Hg}(0)$. To choose the appropriate spatial scale for the core-shell fiber, we analyzed the balance of reaction and transport rates within the community. For spatial structure to affect the kinetics of degradation, the reaction network must meet two requirements: the kinetics of the reactions must be nonlinear 38 and the scale of the structure must be appropriate for the reactions.39 A core-shell system for mercuric ion reduction and PCP degradation satisfies both requirements. First, nonlinearity is inherent in this system, because the rate of degradation of PCP strongly depends on the concentration of $\mathrm{Hg}$ (II) ions (Figure S6). Second, the appropriate scale of the spatial structure is defined by the Damköhler number, $D a$, which relates the time scale of diffusion of $\mathrm{Hg}(\mathrm{II})$ ions through the shell layer, $t_{\mathrm{D}}$, to the time scale ( half life) of reduction of $\mathrm{Hg}(\mathrm{II})$ ions by $R$. metallidurans, $t_{R}$. Stated simply, the $D a$ analysis predicts that if the shell layer is too thin, the $S$. chlorophenolicum cells inside the core layer will be insufficiently protected; the $\mathrm{Hg}$ (II) ions will diffuse into the core layer faster than the $R$. metallidurans cells in the shell layer can reduce the $\mathrm{Hg}(\mathrm{II})$ to $\mathrm{Hg}(0)$. On the other hand, if the shell layer is too thick, the kinetics of the PCP degradation in the core layer will be limited because the amounts of available substrates (and possibly oxygen and nutrients) will be limited by the time of diffusion through the shell layer. For a core-shell system, $t_{\mathrm{D}} \sim x^{2} / 2 D$, where $x[\mathrm{~m}]$ is the thickness of the shell layer and $D\left[\mathrm{~m}^{2} \cdot \mathrm{s}^{-1}\right]$ is the diffusion coefficient of the substrate through the shell layer. For the scale of the spatial structure to be appropriate, $t_{\mathrm{D}}$ must be on the order of $t_{\mathrm{R}}$. Here, the substrate is $\mathrm{Hg}$ (II) ions and their diffusion coefficient through alginate gel is $\sim 3 \times 10^{-10} \mathrm{~m}^{2} \cdot \mathrm{s}^{-1}$. ${ }^{40}$ The time scale of reduction of $\mathrm{Hg}(\mathrm{II})$ ions by $R$. metallidurans was more rapid than the resolution of our measurements; the specific rate was above $0.5 \mathrm{fmol} \cdot \mathrm{CFU}^{-1} \cdot \mathrm{min}^{-1}$, indicating that under our conditions $t_{\mathrm{R}}$ is $\sim$ one minute or shorter. Thus, for $t_{\mathrm{D}}$ to match $t_{\mathrm{R}}, x$ must be $\sim 200 \mu \mathrm{m}$. Da number analysis of this specific system predicts optimal structure on the scale of a few hundred micrometers, similar to ones observed in nature ${ }^{18}$ (e.g., as seen in Figure 1), and similar to the one found experimentally for synthetic spatially structured communities constructed in microfluidic devices. ${ }^{7}$

We constructed an appropriately scaled core-shell fiber system containing cells suspended in calcium alginate gel ( $2 \% \mathrm{w} / \mathrm{v}$, final concentration of sodium alginate solution) using previously described microfluidic laminar flow technologies ${ }^{41}$, 42 (see Figure 2, Figure S7, and Experimental section). Using the seven-barrel capillary system, fibers with seven independently controlled sections could be constructed (Figure $2 \mathrm{~d}$ and e). In preliminary experiments, we found that the degradation of PCP was not dependent on the presence of alginate. Agarose fibers also enabled degradation of PCP, at a slightly higher rate than Caalginate fibers, but we chose Ca-alginate fibers because alginate was easier to use and handle. Fibers contained $S$. chlorophenolicum cells in the core layer ( $163 \mu \mathrm{m}$ diameter, RSD $2.3 \%, \mathrm{n}=11$, measured at different positions along the same fiber) and $R$. metallidurans cells in the shell layer $(379 \mu$ m outer diameter, RSD $1.5 \%, \mathrm{n}=11$, measured at different 
positions along the same fiber). When we constructed the core-shell fiber system, the core layer was extruded out via one capillary and the shell layer was extruded out via six capillaries in a device (Figure $2 \mathrm{~b}$ and e). Accordingly, the cell densities of the two species were adjusted to keep the total number of cells of each species the same in the fiber: the cell density of $S$. chlorophenolicum in the core was $\sim 5 \times 10^{8} \mathrm{CFU} \cdot \mathrm{mL}^{-1}$; the cell density of $R$. metallidurans in the shell was $1 / 6$ of $\sim 5 \times 10^{8} \mathrm{CFU} \cdot \mathrm{mL}^{-1}$, or $\sim 8.3 \times 10^{7} \mathrm{CFU} \cdot \mathrm{mL}^{-1}$. We found that this spatially structured community rapidly degraded PCP even in the presence of $\mathrm{Hg}$ (II) ions (Figure 3b). The rate of PCP degradation by the core-shell fiber system was slower than that by $S$. chlorophenolicum in liquid culture (Figure $3 \mathrm{~b}$ vs. Figure S2). This was presumably due to limited mass transport of PCP and, potentially, nutrients and oxygen, into the interior of the fiber, although we did not attempt to distinguish these potential reasons. Nevertheless, the core-shell fiber system was able to degrade nearly all the PCP present over 24 hrs (Figure 3b). Furthermore, as a control experiment, we prepared fibers with a spatial organization of $R$. metallidurans in the core layer and $S$. chlorophenolicum in the shell layer, and observed a significantly decreased capacity for PCP degradation (Figure 5). When $S$. chlorophenolicum cells were constrained in the core layer and $R$. metallidurans cells were deposited in the shell layer (black triangles; 'original'), these fibers completely degraded all of the PCP in the presence of $\mathrm{Hg}(\mathrm{II})$ ions. In contrast, when $R$. metallidurans cells were constrained in the core layer and $S$. chlorophenolicum cells were constrained in the shell layer (red inverted triangles; 'inverted'), these fibers degraded only 50\% of the PCP in the presence of $\mathrm{Hg}$ (II) ions. Therefore, the specific spatial organization of the two bacterial species within the core-shell fiber system is required for successful degradation of the PCP and $\mathrm{Hg}(\mathrm{II})$ mixture.

\section{Conclusions}

These results suggest that just as complex structures are built by carefully arranging 'Lego' blocks, complex chemical functions can be performed by arranging individual species within a spatial structure to construct a synthetic community. Microfluidic techniques are attractive for constructing these structured communities, both within a microfluidic device ${ }^{7}$ and scaling them up into structures usable outside of devices, as shown here. The devicefree structured community that we developed can be used in applications such as environmental remediation, biomedical probes, probiotic therapeutics, and microbial aerobic-anaerobic interfaces, especially as additional investigations, and the necessary field testing (not performed in this paper), are carried out. This approach would further benefit from materials with controlled mechanical and chemical properties ${ }^{43}, 44$ that facilitate longterm function of communities, and from particles and fibers with mass-production technologies. $45^{-} 48$ The Damköhler number can be adjusted into the desired range by adjusting the dimensions and transport properties of the materials used to build the communities, the reaction rates, and the densities of microbes within the communities. Modifying the relative geometric arrangements of microbes within the structures (another possible arrangement is shown in Figure 2d, e) may be used to control communication of microbes and the sequence of functions that are required.

This approach provides an alternative to genetic engineering to carry out multiple biological functions. Structured microbial communities of non-modified strains can be used in situations where genetically modified organisms are undesirable, such as in environmental remediation, medicine, and agriculture. If the use of genetically modified organisms is not problematic, genetic engineering can be combined with spatial structure; for example, structured communities of modified organisms can be used within bioreactors to maximize reaction yields. Pre-structuring a microbial community may also be beneficial when a synthetic system needs to be constructed rapidly, especially with strains not currently amendable to rapid engineering. It may also be attractive in cases when the system can be 
optimized by varying the spatial structure rather than re-engineering of strains (e.g. to vary the reaction rates or the strength of coupling among reactions). This approach of prestructuring microbial communities is applicable to any set of functions where diffusible molecules are exchanged among microorganisms, such as signaling molecules or intermediates of reactions. This microfluidic-based approach for creating synthetic microbial communities may improve synthesis, degradation, modification, and regulation of compounds such as small molecules, biopolymers, and supramolecular assemblies. In the context of human and animal health, it provides an intriguing opportunity to create a "microbiome on a pill" that functions beyond conventional probiotic approaches. Chemical, biological, and technical intuition, coupled with research on natural communities that explores the functions and interactions of their microbial constituents ${ }^{2,5}, 20,49^{-54}$ will provide this approach with guidance and inspiration.

\section{Experimental}

\section{Cultivation of microorganisms and culture media}

Bacterial strains of Sphingobium chlorophenolicum (ATCC 53874) and Ralstonia metallidurans (ATCC 43123) were purchased from the American Type Culture Collection. $S$. chlorophenolicum and $R$. metallidurans cells were respectively enriched in sterilized PCP-Mercury (PM) media $\left(0.5 \mathrm{~g} \cdot \mathrm{L}^{-1}\right.$ sodium gluconate, $0.1 \mathrm{~g} \cdot \mathrm{L}^{-1}$ ammonium acetate, 0.25 $\mathrm{g} \cdot \mathrm{L}^{-1}$ yeast extract, $0.25 \mathrm{~g} \cdot \mathrm{L}^{-1}$ casamino acid, $0.1 \mathrm{~g} \cdot \mathrm{L}^{-1}$ lactic acid, $2.5 \mathrm{~g} \cdot \mathrm{L}^{-1}$ mono sodium glutamate, $0.5 \mathrm{~g} \cdot \mathrm{L}^{-1}$ sodium nitrate, $0.82 \mathrm{~g} \cdot \mathrm{L}^{-1}$ potassium phosphate (dibasic), $0.19 \mathrm{~g} \cdot \mathrm{L}^{-1}$ potassium phosphate (monobasic), $0.1 \mathrm{~g} \cdot \mathrm{L}^{-1}$ magnesium sulfate (heptahydrate), and 0.005 $\mathrm{g} \cdot \mathrm{L}^{-1}$ iron(II) sulfate (heptahydrate); $\mathrm{pH} 7.2$ ) at $30^{\circ} \mathrm{C}$ for $12 \mathrm{~h}$. In the case of liquid culture, agitation was kept at $180 \mathrm{rpm}$.

For the seed culture of S. chlorophenolicum cells, a pentachlorophenol (PCP; 98\% purity, Aldrich) stock solution was prepared by dissolving PCP in $1 \mathrm{M}$ sodium hydroxide solution at $100 \mathrm{mM}$ (final concentration), then diluted in PM media to $10 \mathrm{mM}$ (final concentration). The $10 \mathrm{mM}$ stock solution of PCP in PM media was then added to the seed culture broth of S. chlorophenolicum cells at $50 \mu \mathrm{M}$ (final concentration) in order to induce the PCP degradation pathway. After $S$. chlorophenolicum cells were exponentially grown in the presence of PCP in PM media, the cell suspension was mixed with a sterilized glycerol stock solution $(40 \%, \mathrm{v} / \mathrm{v})$ at a $1: 1$ volume ratio, then stored in a $-70^{\circ} \mathrm{C}$ deep freezer.

For the seed culture of $R$. metallidurans cells, a mercury(II) chloride $\left(\mathrm{HgCl}_{2} ; 99.5 \%\right.$ purity, Acros Organics) stock solution was prepared by dissolving $\mathrm{HgCl}_{2}$ in D.I. water at $100 \mathrm{mM}$ (final concentration), then diluted in PM media to $10 \mathrm{mM}$ (final concentration). The $10 \mathrm{mM}$ stock solution of $\mathrm{HgCl}_{2}$ in $\mathrm{PM}$ media was then added to the seed culture of $R$. metallidurans cells at $50 \mu \mathrm{M}$ (final concentration) in order to induce the production of mercury reductases. $R$. metallidurans was subcultured every 3 days on fresh agar media comprised of sterilized Difco tryptic soy agar (TSA; $40 \mathrm{~g} \cdot \mathrm{L}^{-1}$; BD Company) media and mercuric ions (Hg(II); 100 $\mu \mathrm{M}$, final concentration), then preserved at $4^{\circ} \mathrm{C}$.

The density of $S$. chlorophenolicum and $R$. metallidurans cells was estimated by measuring the optical density using a spectrophotometer (8453 UV-Visible Spectrophotometer, Agilent Technologies) at $600 \mathrm{~nm}$. For growth profiling of both $S$. chlorophenolicum and $R$. metallidurans cells, cells were individually cultured in a sterile 96-well plate (Costar, Corning Incorporated) using different conditions of medium. The optical density of the culture broth was intermittently measured at $600 \mathrm{~nm}$ by using a microplate reader (POLARstar Omega, BMG Labtech). 
In Figure 2c, the fluorescence-labeled bacterial strains used were i) green fluorescent protein (GFP)-labeled Escherichia coli containing PUCP24/EGFP plasmids in E. coli K12 YMel-1 host and ii) red fluorescent protein (RFP)-labeled E. coli containing DsRed encoding plasmids in $E$. coli DH10B host. The GFP-labeled E. coli was constructed in our laboratory. The RFP-labeled E. coli strain was provided by Professor Benjamin Glick of the University of Chicago. GFP-labeled E. coli was cultured in sterilized tryptic soy broth (TSB, BD Company) media containing $100 \mathrm{mg} \cdot \mathrm{L}^{-1} \mathrm{kanamycin}$ and $20 \mathrm{mg} \cdot \mathrm{L}^{-1}$ gentamicin. RFPlabeled E. coli was cultured in sterilized TSB media containing $100 \mathrm{mg} \cdot \mathrm{L}^{-1}$ ampicillin. After both strains were suspended in a sterilized sodium chloride solution $(0.9 \%, \mathrm{w} / \mathrm{v})$, the numbers of fluorescent cells of each strain were diluted to be similar using an epifluorescence microscope (IRE2, Leica).

In Figure 2e, the fluorescence-labeled bacterial strains used were i) red fluorescent protein (RFP)-labeled E. coli containing DsRed encoding plasmids in E. coli DH10B host, provided by Professor Benjamin Glick of the University of Chicago. ii) Salmonella enterica (ATCC 14028), purchased from the American Type Culture Collection (ATCC), iii) Pseudomonas aeruginosa containing the plasmid pMHLB, which encodes the lasB reporter PlasBgfp(ASV), which causes the cells to express GFP at high cell density. This strain was generously provided by Professor Soren Molin.[55] RFP-labeled E. coli was cultured in sterilized TSB media containing $100 \mathrm{mg} \cdot \mathrm{L}^{-1}$ ampicillin at $30^{\circ} \mathrm{C}$. S. enterica was cultured in LB medium at $30^{\circ} \mathrm{C}$. GFP-expressing $P$. aeruginosa was cultured in LB medium with 100 $\mathrm{mg} \cdot \mathrm{L}^{-1}$ ampicillin at $30^{\circ} \mathrm{C}$. All three strains were cultured for 8 hours, then immediately used to construct the core-shell fiber.

\section{Fabrication of devices}

A seven-barrel capillary (World Precision Instruments, USA) with an outer diameter (O.D.) of $3 \mathrm{~mm}$ was pulled by using a vertical pipette puller (Model 700, David Kopf Instruments, USA) so that the O.D. at the tip was $\sim 0.6 \mathrm{~mm}$. Then the seven-barrel capillary (SBC) was cut to a length of $2 \mathrm{~cm}$ by using a capillary cutting stone (Hampton Research, USA). Seven fused silica capillaries ( $4 \mathrm{~cm}$ length, $300 \mu \mathrm{m}$ inner diameter (I.D.), $420 \mu \mathrm{m}$ O.D., Polymicro, USA) were inserted through the seven inlets of the SBC and then sealed with epoxy (Devcon, USA). Each capillary was attached to a piece of Teflon tubing (20 cm length, 360 $\mu \mathrm{m}$ I.D., Weico Wire \& Cable, Edgewood, NY). Another short piece of Teflon tubing $(3 \mathrm{~cm}$ length, $1.5 \mathrm{~mm}$ I.D., Upchurch Scientific, USA) with a conical tip (400 $\mu \mathrm{m}$ I.D.) that had been elongated by using a vertical pipette puller (Model 700, David Kopf Instruments, USA) was sealed onto the tapered tip of the SBC with epoxy. Devices were sterilized by rinsing with $70 \%$ (v/v) ethanol and then baking in a $125^{\circ} \mathrm{C}$ oven for $30 \mathrm{~min}$ prior to use.

\section{Construction of fibers}

To construct the core-shell fiber system, both S. chlorophenolicum and R. metallidurans cells were cultured in PM media at $30^{\circ} \mathrm{C}$ overnight. S. chlorophenolicum was grown in the presence of PCP and R. metallidurans was grown in the presence of $\mathrm{Hg}(\mathrm{II})$ to induce their respective functions. Next, the culture broth was washed with fresh PM media twice. Then the number of live cells was estimated by staining with live/dead dye (Live/Dead BacLight Bacterial viability kit, Molecular Probes) and counting cells under an epi-fluorescence microscope (DMI $6000 \mathrm{~B}$, Leica). A live cell density of $\sim 10^{9} \mathrm{CFU} \cdot \mathrm{mL}^{-1}$ for both species was required to make fibers.

To prepare the cell suspensions in sodium alginate solutions, S. chlorophenolicum and $R$. metallidurans bacterial cells were diluted with PM media and mixed with autoclaved 4\% (w/ v) sodium alginate solution (from brown algae, Sigma) at a 1:1 volume ratio. Since the device was designed such that only one capillary was used for the core layer and six 
capillaries were used for the shell layer, the cell density of the species that was deposited in the shell layer was 1/6 the cell density of the species that was deposited in the core layer. The total number of both species in the whole fiber was the same, and the overall cell density of both species in a tube containing the reaction media and fibers was eventually identical. The resulting cell suspension in sodium alginate solution was mixed by using a vortex machine for $30 \mathrm{sec}$.

Each cell suspension in sodium alginate solution was then infused into the SBC device at flow rate of $100 \mu \mathrm{L} \cdot \mathrm{min}^{-1}$. The tip of the SBC was immersed in a solution of calcium chloride $(100 \mathrm{mM})$ so that as fibers were extruded, the calcium ions would crosslink the alginate polymer chains into a gel matrix and a calcium alginate matrix would form around the cells. The total volume of the core-shell fiber system was held constant at $420 \mu \mathrm{L}$ by setting the volume of infusion at $60 \mu \mathrm{L}$. To construct core-shell fibers containing $S$. chlorophenolicum cells in the core layer and R. metallidurans cells in the shell layer, a disposable syringe ( $1 \mathrm{~mL}$; Becton Dickinson \& CO, USA) with a $27 \mathrm{G} \times 1 / 2$ " needle (Becton Dickinson \& CO, USA) was filled with the mixture of S. chlorophenolicum cell suspension and sodium alginate solution (final cell density was $\sim 5 \times 10^{8} \mathrm{CFU} \cdot \mathrm{mL}^{-1}$ ), and then the syringe was connected to barrel \#1 (Figure 2b) of the device. Six disposable syringes $(1 \mathrm{~mL}$; $\mathrm{BD})$ containing the mixture of $R$. metallidurans cell suspension and sodium alginate solution (final cell density was $\sim 8.3 \times 10^{7} \mathrm{CFU} \cdot \mathrm{mL}^{-1}$ ) were then connected to barrels \#2 through \#7. All seven syringes were attached to a PHD 2000 Infusion syringe pump (Harvard Apparatus, USA) by using a 10-syringe rack (Harvard Apparatus, USA). To construct inverted fibers, we followed the same procedure as above, but switched the species in the core and shell layers.

\section{Degradation of PCP and reduction of $\mathrm{Hg}$ (II)}

Degradation of PCP and reduction of $\mathrm{Hg}$ (II) were performed in a sterile test tube (Falcon, 14 $\mathrm{mL}$ polystyrene round-bottom tube, $\mathrm{BD})$ containing sterilized $\mathrm{PM}$ media $(3 \mathrm{~mL}$, working volume). In experiments with core-shell fibers, $420 \mu \mathrm{L}$ of the fibers (gel volume) was added to the test tube. An aliquot of PCP solution or an aliquot of $\mathrm{Hg}$ (II) solution or both was added to the media from the stock solutions that are described above. When degradation of PCP and reduction of $\mathrm{Hg}(\mathrm{II})$ were performed simultaneously, the core-shell fiber systems were pre-incubated in PM media containing only PCP $(100 \mu \mathrm{M})$ for $12 \mathrm{~h}$, then the main experiment was performed by switching the core-shell fibers into fresh media containing PCP $(120 \mu \mathrm{M})$ and $\mathrm{HgCl}_{2}(120 \mu \mathrm{M})$. To optimize the degradation of PCP in all experiments (Figure $\mathrm{S} 1$ ), the $\mathrm{pH}$ of the culture broth was intermittently measured by using $\mathrm{pH}$ paper (Hydrion Papers, Micro Essential Laboratory). If the $\mathrm{pH}$ of the culture broth was too high, the $\mathrm{pH}$ was adjusted to $\sim 7$ by adding a $\mathrm{HCl}$ solution $(1 \mathrm{M})$, which was filter-sterilized by using a $0.45 \mu \mathrm{m}$ pore-sized filter (Steriflip, Millipore). Samples of the culture broth $(50 \mu \mathrm{L}$ or $100 \mu \mathrm{L}$ ) were intermittently taken for the analysis of either PCP or total mercury, and these samples were diluted either three or five times with a sterile $\mathrm{HCl}$ solution $(3 \mathrm{M})$ in order to stop further reactions. The $\mathrm{HCl}$ solution was sterilized by using a $0.45 \mu \mathrm{m}$ poresized filter (Steriflip, Millipore) prior to use. In all core-shell fiber experiments, calcium chloride solution (1 $\mathrm{mM}$, final concentration) was added to the tube. We confirmed that the presence of $\mathrm{Ca}^{2+}$ ions was not toxic to either species, and affected neither PCP degradation nor $\mathrm{Hg}(\mathrm{II})$ ion reduction (data not shown). While standard errors calculated from two measurements are generally not reliable, preliminary experiments (data not shown, $n=3-5$ ) showed high reproducibility with relatively small standard errors. Additionally, all experiments were accompanied by control experiments of liquid mono culture for both PCP degradation and $\mathrm{Hg}$ (II) reduction at the same cell density and the same PCP and total $\mathrm{Hg}$ concentrations. These control experiments gave a reliable extrapolation that the main 
experiments with core-shell fibers were highly reproducible. Therefore, all subsequent degradation experiments reported here were done in duplicate.

To normalize the data in Figure 5, the PCP concentration at each time point was divided by the initial concentration of $\mathrm{PCP}$ at $0 \mathrm{~h}$ for each experimental setup.

\section{Quantitative analysis of pentachlorophenol and mercury}

The concentration of pentachlorophenol (PCP) was analyzed by using a high performance liquid chromatography (HPLC) system (Varian Inc.). An aliquot of each sample taken intermittently was diluted with a sterile $\mathrm{HCl}$ solution $(3 \mathrm{M})$ either three or five times depending on the expected concentration. The $\mathrm{HCl}$ solution was sterilized by using a 0.45 $\mu \mathrm{m}$ pore-sized filter (Steriflip, Millipore) prior to use. After the diluted sample was centrifuged at 10,000 rpm for 15 min (Centrifuge 5424, Eppendorf), the supernatant was analyzed using an HPLC system. The sample conveyed by the autosampler system (ProStar 325, Varian Inc.) was flowed into the C18 column (Hypersil GOLD, 150×4.6 mm, $5 \mu \mathrm{m}$ particle size, Thermo Scientific) equipped with a guard column (Hypersil GOLD, 10×4 mm, $5 \mu \mathrm{m}$ particle size, Thermo Scientific) in the isocratic elution of acetonitrile (with $0.1 \%$ acetic acid, Sigma) and D.I. water (70:30, v/v) at $0.6 \mathrm{~mL} \cdot \mathrm{min}^{-1}$ by using a dual pump system (ProStar 210, Varian Inc.). The PCP peak was monitored by the UV/Vis detector at the wavelength of $210 \mathrm{~nm}$ (ProStar 410, Varian Inc.). Chromatogram results were analyzed by using Galaxie software (Varian Inc.). We estimated the concentration of PCP by using a calibration curve which plotted various concentrations of PCP and their corresponding peak areas. In figures, the concentration of PCP was represented by [PCP].

Mercury analysis was performed by the STAT Analysis Corporation (Chicago, IL) by using cold vapor atomic absorption (Model 6000A, CETAC Technologies). In all cases in this paper, 'mercury concentration' indicates the concentration of the total mercury at all oxidation states. In figures, the concentration of the total mercury at all states was represented by $[\mathrm{Hg}]_{\mathrm{t}}$

\section{Data acquisition and analysis of microscopic images}

Fluorescent images (Figures 2c,e and S7) were acquired by using an epi-fluorescence microscope (IRE2, Leica) equipped with a $5 \times(0.15 \mathrm{NA})$ objective and either an L5 (for GFP-labeled E. coli and P. aeruginosa strains) or a TX2 filter (for RFP-labeled E. coli strain) sets (Leica), which were coupled with a cooled CCD camera (12-bit, 1344×1024 resolution; Hamamatsu Photonics) with a 1.0x coupler. Fluorescent images of both GFPlabeled cells in a shell layer and RFP-labeled $E$. coli cells in a core layer were taken with an exposure time of $500 \mathrm{~ms}$ and $100 \mathrm{~ms}$, respectively. For the overlay of fluorescent images taken by an L5 filter and a TX2 filter set (Figure 2c and e), the acquired fluorescent images were processed by using MetaMorph image software (Ver 6.3r1, Molecular Devices). In Figures $2 \mathrm{c}$ and e, the fluorescent images taken with an L5 filter were processed with the low scale value of 230 and the high scale value of 290 , whereas the fluorescent images taken with a TX2 filter were processed with the low scale value of 200 and the high scale value of 1500. In Figure S7a, the bright field image was processed with the low scale value of 1000 and the high scale value of 3000 at $2 \mathrm{~ms}$ exposure time. The scale values for the fluorescent images in Figure S7 were the same as in Figures 2c and e.

\section{Supplementary Material}

Refer to Web version on PubMed Central for supplementary material. 


\section{Acknowledgments}

This work was supported by the NSF CRC Grant CHE-0526693 and the NIH Director's Pioneer Award (1DP1 OD003584). Part of this work was performed at the microfluidics facility at the Chicago Materials Science and Research Center (Chicago MRSEC). HJK is a recipient of the Leo P. Kadanoff and Stuart A. Rice Fellowship from the Chicago MRSEC. Mercury analysis was performed by the STAT Analysis Corporation. We thank Chuan He for invaluable discussions and for the use of equipment, Songzi Kou for experimental assistance with the design and implementation of the experiment shown in Figure 2d and e, and Elizabeth B. Haney and Heidi Park for contributions to writing and editing this manuscript.

\section{Notes and references}

1. Andrianantoandro E, Basu S, Karig DK, Weiss R. Mol. Syst. Biol 2006;2:0028. [PubMed: 16738572]

2. Brenner K, You LC, Arnold FH. Trends Biotechnol 2008;26:483-489. [PubMed: 18675483]

3. Hasty J, McMillen D, Collins JJ. Nature 2002;420:224-230. [PubMed: 12432407]

4. Lee SK, Chou H, Ham TS, Lee TS, Keasling JD. Curr. Opin. Biotechnol 2008;19:556-563. [PubMed: 18996194]

5. de Lorenzo V. Curr. Opin. Biotechnol 2008;19:579-589. [PubMed: 19000761]

6. Song H, Payne S, Gray M, You LC. 2009;5:929-935.

7. Kim HJ, Boedicker JQ, Choi JW, Ismagilov RF. Proc. Natl. Acad. Sci. USA 2008;105:1818818193. [PubMed: 19011107]

8. Peiru S, Gramajo H, Menzella HG. Method. Enzymol 2009;459:319-337.

9. Beer LL, Boyd ES, Peters JW, Posewitz MC. Curr. Opin. Biotechnol 2009;20:264-271. [PubMed: 19560336]

10. Gupta V, Garg R. Indian J. Med. Microbiol 2009;27:202-209. [PubMed: 19584499]

11. Alisi C, Musella R, Tasso F, Ubaldi C, Manzo S, Cremisini C, Sprocati AR. Sci. Total Environ 2009;407:3024-3032. [PubMed: 19201450]

12. Demirel B, Neumann L, Scherer P. Eng. Life Sci 2008;8:390-398.

13. Dechesne A, Or D, Smets BF. FEMS Microbiol. Ecol 2008;64:1-8. [PubMed: 18312376]

14. Kaeberlein T, Lewis K, Epstein SS. Science 2002;296:1127-1129. [PubMed: 12004133]

15. Ohno M, Okano I, Watsuji TO, Kakinuma T, Ueda K, Beppu T. Biosci. Biotechnol. Bioch 1999;63:1083-1090.

16. Ferrari BC, Binnerup SJ, Gillings M. Appl. Environ. Microbiol 2005;71:8714-8720. [PubMed: 16332866]

17. Fernandez AS, Hashsham SA, Dollhopf SL, Raskin L, Glagoleva O, Dazzo FB, Hickey RF, Criddle CS, Tiedje JM. Appl. Environ. Microbiol 2000;66:4058-4067. [PubMed: 10966429]

18. Sekiguchi Y, Kamagata Y, Nakamura K, Ohashi A, Harada H. Appl. Environ. Microbiol 1999;65:1280-1288. [PubMed: 10049894]

19. Dechesne A, Pallud C, Debouzie D, Flandrois JP, Vogel TM, Gaudet JP, Grundmann GL. Soil Biol. Biochem 2003;35:1537-1546.

20. O'Donnell AG, Young IM, Rushton SP, Shirley MD, Crawford JW. Nat. Rev. Microbiol 2007;5:689-699. [PubMed: 17676055]

21. Weber R, Gaus C, Tysklind M, Johnston P, Forter M, Hollert H, Heinisch E, Holoubek I, LloydSmith M, Masunaga S, Moccarelli P, Santillo D, Seike N, Symons R, Torres J, Verta M, Varbelow G, Vijgen J, Watson A, Costner P, Woelz J, Wycisk P, Zennegg M. Environ. Sci. Pollut. R 2008;15:363-393.

22. Weber R, Tysklind M, Gaus C. Environ. Sci. Pollut. R 2008;15:96-100.

23. Verta M, Kiviranta H, Salo S, Malve O, Korhonen M, Verkasalo P, Ruokojarvi P, Rossi E, Hanski A, Paatalo K, Vartiainen T. Environ. Sci. Pollut. R 2009;16:95-105.

24. Hryhorczuk DO, Wallace WH, Persky V, Furner S, Webster JR Jr, Oleske D, Haselhorst B, Ellefson R, Zugerman C. Environ. Health Persp 1998;106:401-408.

25. Passivirta J, Särkkä J, Surma-Aho K, Humppi T, Kuokkanen T, Marttinen M. Chemosphere 1983;12:239-252. 
26. Sandrin TR, Maier RM. Environ. Health Persp 2003;111:1093-1101.

27. Kuo CW, Genthner BRS. Appl. Environ. Microbiol 1996;62:2317-2323. [PubMed: 16535351]

28. Riis V, Babel W, Pucci OH. Chemosphere 2002;49:559-568. [PubMed: 12430643]

29. Codina JC, Cazorla FM, Perez-Garcia A, de Vicente A. Environ. Toxicol. Chem 2000;19:15521558.

30. McAllister KA, Lee H, Trevors JT. Biodegradation 1996;7:1-40.

31. Barkay, T.; Wagner-Dobler, I. Advances in Applied Microbiology. Laskin, AI.; Bennet, JW.; Gadd, GM., editors. Vol. vol. 57. San Diego, CA: Elsevier Academic Press Inc; 2005. p. 1-52.

32. Lin Q, Zhao HM, Chen YX. J. Environ. Sci. Heal. B 2007;42:551-557.

33. Cai M, Xun LY. J. Bacteriol 2002;184:4672-4680. [PubMed: 12169590]

34. Alloway, BJ. Heavy metals in soils. London: Blackie Academic \& Professional; 1995.

35. Mergeay M, Monchy S, Vallaeys T, Auquier V, Benotmane A, Bertin P, Taghavi S, Dunn J, van der Lelie D, Wattiez R. FEMS Microbiol. Rev 2003;27:385-410. [PubMed: 12829276]

36. Rossy E, Champier L, Bersch B, Brutscher B, Blackledge M, Coves J. J. Biol. Inorg. Chem 2004;9:49-58. [PubMed: 14624351]

37. Crawford RL, Jung CM, Strap JL. Biodegradation 2007;18:525-539. [PubMed: 17123025]

38. Pompano RR, Li HW, Ismagilov RF. Biophys. J 2008;95:1531-1543. [PubMed: 18424502]

39. Kastrup CJ, Runyon MK, Shen F, Ismagilov RF. Proc. Natl. Acad. Sci. USA 2006;103:1574715752. [PubMed: 17043240]

40. Deckwer WD, Becker FU, Ledakowicz S, Wagner-Dobler I. Environ. Sci. Technol 2004;38:18581865. [PubMed: 15074700]

41. Hu M, Kurisawa M, Deng R, Teo CM, Schumacher A, Thong YX, Wang L, Schumacher KM, Ying JY. Biomaterials 2009;30:3523-3531. [PubMed: 19328545]

42. Kenis PJA, Ismagilov RF, Whitesides GM. Science 1999;285:83-85. [PubMed: 10390366]

43. Choi NW, Cabodi M, Held B, Gleghorn JP, Bonassar LJ, Stroock AD. Nat. Mater 2007;6:908-915. [PubMed: 17906630]

44. Su J, Zheng Y, Wu H. Lab Chip 2009;9:996-1001. [PubMed: 19294313]

45. Euliss LE, DuPont JA, Gratton S, DeSimone J. Chem. Soc. Rev 2006;35:1095-1104. [PubMed: 17057838]

46. Gensheimer M, Becker M, Brandis-Heep A, Wendorff JH, Thauer RK, Greiner A. Adv. Mater 2007;19:2480-2482.

47. Gratton SEA, Williams SS, Napier ME, Pohlhaus PD, Zhou ZL, Wiles KB, Maynor BW, Shen C, Olafsen T, Samulski ET, Desimone JM. Accounts Chem. Res 2008;41:1685-1695.

48. Salalha W, Kuhn J, Dror Y, Zussman E. Nanotechnology 2006;17:4675-4681.

49. Cardenas E, Wu WM, Leigh MB, Carley J, Carroll S, Gentry T, Luo J, Watson D, Gu B, GinderVogel M, Kitanidis PK, Jardine PM, Zhou J, Criddle CS, Marsh TL, Tiedje JA. Appl. Environ. Microbiol 2008;74:3718-3729. [PubMed: 18456853]

50. Martiny JBH, Bohannan BJM, Brown JH, Colwell RK, Fuhrman JA, Green JL, Horner-Devine MC, Kane M, Krumins JA, Kuske CR, Morin PJ, Naeem S, Ovreas L, Reysenbach AL, Smith VH, Staley JT. Nat. Rev. Microbiol 2006;4:102-112. [PubMed: 16415926]

51. Vogl K, Wenter R, Dressen M, Schlickenrieder M, Ploscher M, Eichacker L, Overmann J. Environ. Microbiol 2008;10:2842-2856. [PubMed: 18707609]

52. Costello EK, Lauber CL, Hamady M, Fierer N, Gordon JI, Knight R. Science 2009;326:16941697. [PubMed: 19892944]

53. Nelson KE, Weinstock GM, Highlander SK, Worley KC, Creasy HH, Wortman JR, Rusch DB, Mitreva M, Sodergren E, Chinwalla AT, Feldgarden M, Gevers D, Haas BJ, Madupu R, Ward DV, Birren B, Gibbs RA, Methe B, Petrosino JF, Strausberg RL, Sutton GG, White OR, Wilson RK, Durkin S, Gujja S, Howarth C, Kodira CD, Kyrpides N, Mehta T, Muzny DM, Pearson M, Pepin K, Pati A, Qin X, Yandava C, Zeng QD, Zhang L, Berlin AM, Chen L, Hepburn TA, Johnson J, McCorrison J, Miller J, Minx P, Nusbaum C, Russ C, Sykes SM, Tomlinson CM, Young S, Warren WC, Badger J, Crabtree J, Markowitz VM, Orvis J, Cree A, Ferriera S, Gillis M, Hemphill LD, Joshi V, Kovar C, Wetterstrand KA, Abouellleil A, Wollam AM, Buhay CJ, Ding Y, Dugan 
S, Fulton LL, Fulton RS, Holder M, Hostetler J, Allen-Vercoe E, Clifton SW, Earl AM, Farmer CN, Giglio MG, Liolios K, Surette MG, Torralba M, Xu Q, Pohl C, Wilczek-Boney K, Zhu DH, Human Microbiome J. Science 2010;328:994-999. [PubMed: 20489017]

54. Turnbaugh PJ, Ley RE, Mahowald MA, Magrini V, Mardis ER, Gordon JI. Nature 2006;444:1027-1031. [PubMed: 17183312]

55. Hentzer M, Riedel K, Rasmussen TB, Heydorn A, Andersen JB, Parsek MR, Rice SA, Eberl L, Molin S, Hoiby N, Kjelleberg S, Givskov M. Microbiology 2002;148:87-102. [PubMed: 11782502] 


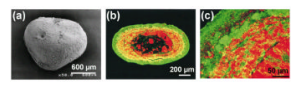

Figure 1.

Images from the previous literature18 illustrating the spatial structure of microbial communities involved in environmental remediation in soil and sludges. a) Scanning electron microphotograph of a thermophilic sludge granule. b) In situ hybridization of sections from a thermophilic sludge granule shows bacterial species (green) surrounding archaebacterial species (red). c) A higher magnification of b). Spatial structure is crucial to balance transport and reactions in these granules. Reprinted from Reference ${ }^{18}$, with permission from the American Society for Microbiology (@ 2009). 


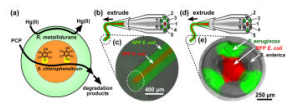

Figure 2.

The spatially structured synthetic microbial community that performs simultaneous degradation of pentachlorophenol (PCP) and reduction of $\mathrm{Hg}$ (II). a) A schematic of the synthetic community. Sphingobium chlorophenolicum aerobically degrades the PCP molecules in the core fiber. Ralstonia metallidurans reduces mercuric ions, $\mathrm{Hg}(\mathrm{II})$, to nontoxic elemental mercury, $\operatorname{Hg}(0)$, in the shell. The chemical transformation from PCP to tetrachloro- $p$-hydroquinone, the key limiting step in PCP degradation, is highlighted. b) A schematic of the process by which the core-shell fiber system was constructed using a seven-barrel capillary. Cells were first suspended in a sodium alginate solution, then suspensions of S. chlorophenolicum (barrel 1) and suspensions of R. metallidurans (barrels 2-7) were extruded from the capillary into a $\mathrm{CaCl}_{2}$ solution, forming a core-shell fiber system consisting of one core part and six shell parts with cells in a calcium alginate matrix (see Experimental section). c) An overlay of fluorescent and bright field microphotographs shows the spatial structure of a core-shell fiber system. This core-shell fiber system contained GFP-labeled Escherichia coli cells in the shell layer and RFP-labeled E. coli cells in the core layer. d) A schematic of the process to create fibers with seven independently controlled sections. Cells were first suspended in a solution of sodium alginate, then suspensions of RFP-labeled E. coli (barrel 1), Salmonella enterica (barrels 2, 4, and 6), and GFP-expressing Pseudomonas aeruginosa (barrels 3, 5, and 7) were extruded into a calcium alginate matrix (see Experimental section). e) An overlay of fluorescent and bright field microphotographs shows the spatial structure of a seven-part fiber system. 


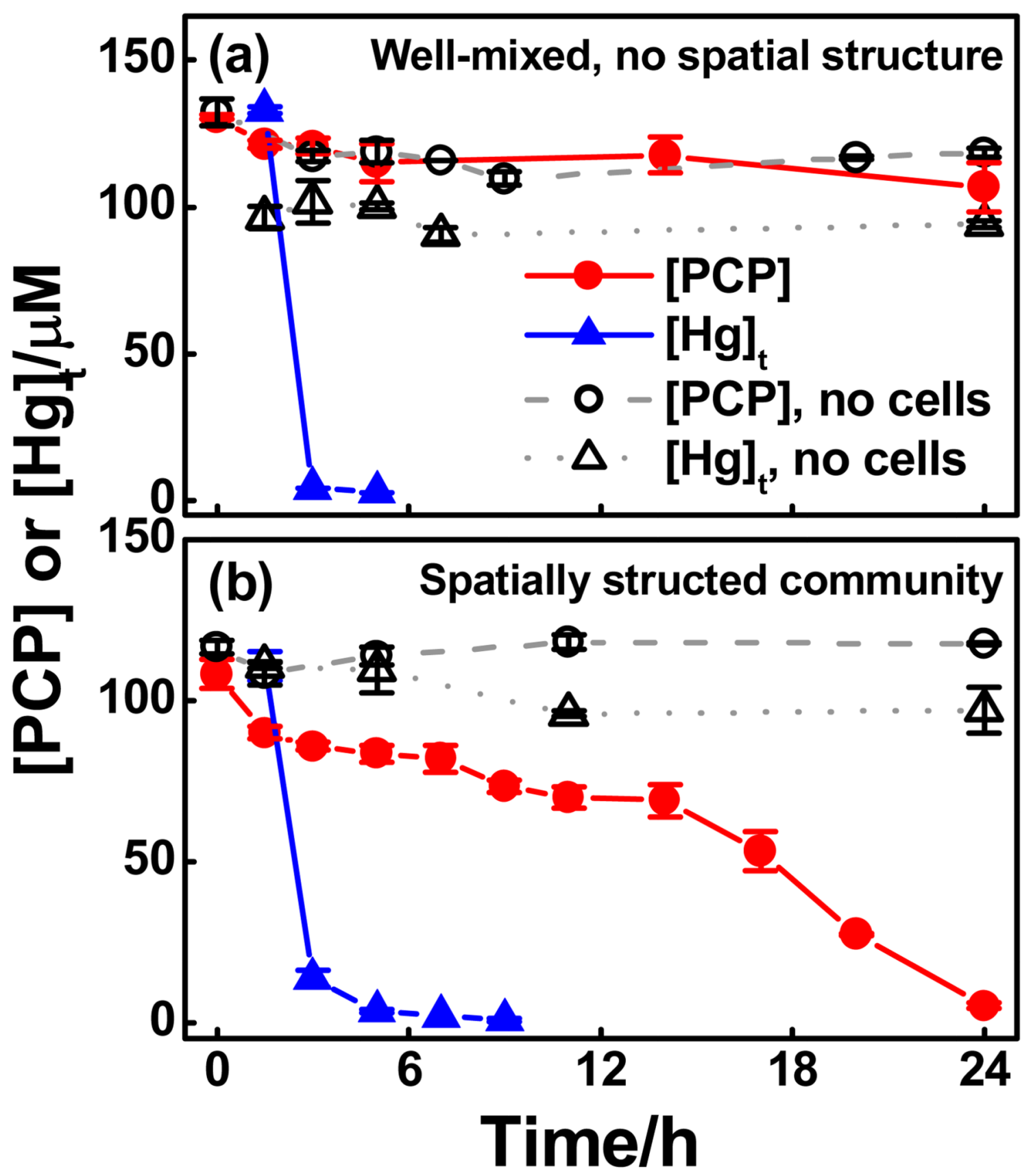

Figure 3.

A well-mixed synthetic microbial community could not simultaneously degrade PCP and reduce $\mathrm{Hg}(\mathrm{II})$, but the same community performed both functions when it was spatially structured. Both communities were exposed to a mixture of PCP (120 $\mu \mathrm{M})$ and $\mathrm{Hg}$ (II) (120 $\mu \mathrm{M})$. PCP was added at time zero, $\mathrm{Hg}(\mathrm{II})$ ions were added at $1.5 \mathrm{~h}$. a) Concentration of PCP (red circles) and $\mathrm{Hg}$ (II) ions (blue triangles) exposed to a well-mixed culture of $S$. chlorophenolicum and $R$. metallidurans as a function of time. The mixture did not degrade PCP but reduced $\mathrm{Hg}$ (II) ions. After $3 \mathrm{~h}$, the level of $\mathrm{Hg}(\mathrm{II})$ was below the detection limit $(0.37 \mu \mathrm{M})$. The cell density of each species was $\sim 5 \times 10^{8} \mathrm{CFU} \cdot \mathrm{mL}^{-1}$. The results of control experiments in the absence of cells are shown with open symbols. b) Concentration of PCP 
(red circles) and $\mathrm{Hg}(\mathrm{II})$ ions (blue triangles) exposed to core-shell fibers made of $S$. chlorophenolicum in the core and $R$. metallidurans in the shell as a function of time. Symbols are the same as in a). The structured community simultaneously degraded PCP and reduced $\mathrm{Hg}$ (II). After $7 \mathrm{~h}$, the level of $\mathrm{Hg}$ (II) was below the detection limit. In the fiber, the cell density of $S$. chlorophenolicum was $\sim 5 \times 10^{8} \mathrm{CFU} \cdot \mathrm{mL}^{-1}$, the cell density of $R$.

metallidurans was $\sim 8.3 \times 10^{7} \mathrm{CFU} \cdot \mathrm{mL}^{-1}$. In both a) and b), the error bars indicate standard errors $(n=2)$. 


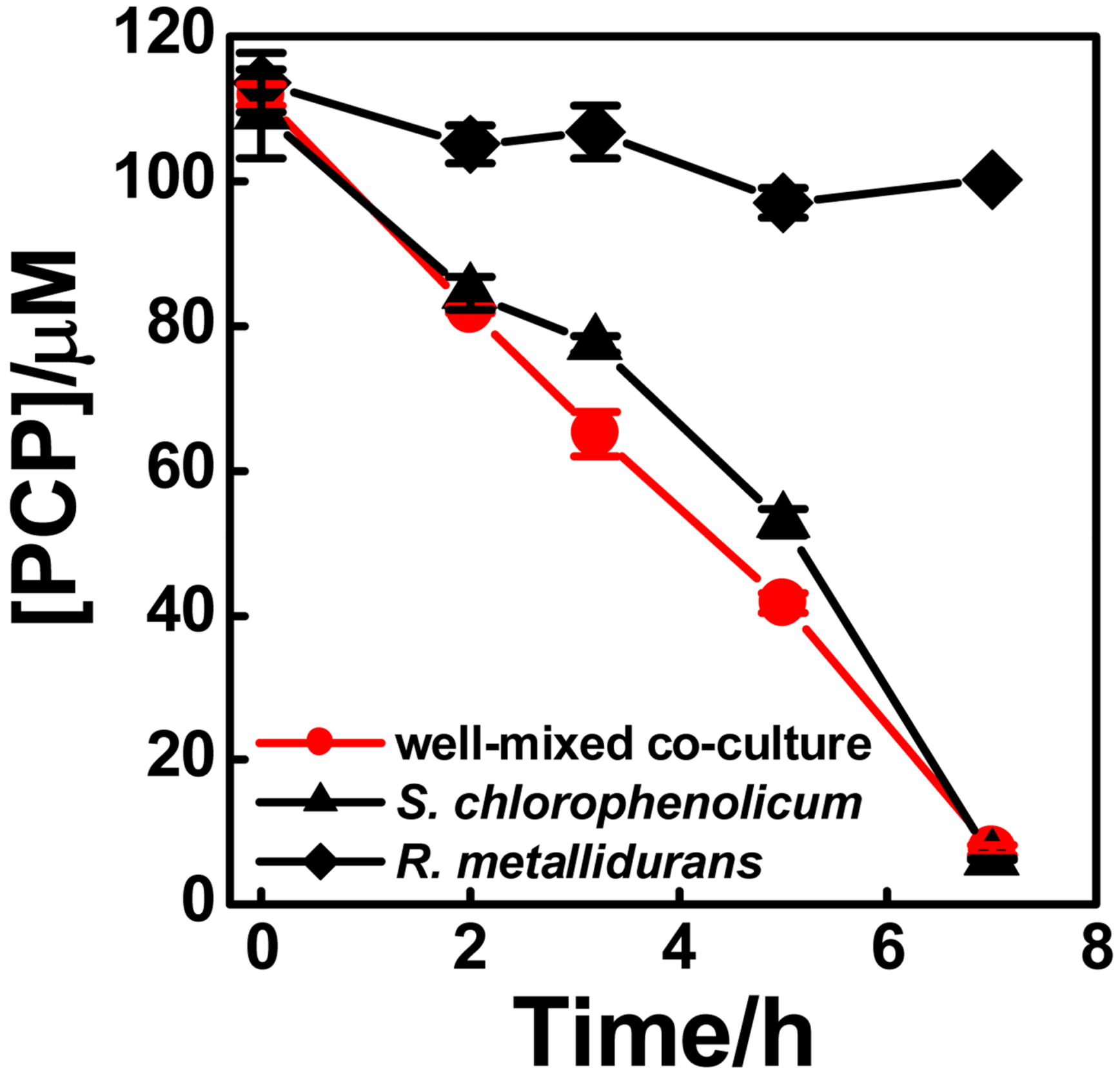

Figure 4.

R. metallidurans cells neither degrade PCP (black diamonds) nor interfere with PCP degradation (red circles). Degradation of PCP was confirmed in both the pure culture of $S$. chlorophenolicum species (black triangles) and the well-mixed co-culture of $R$. metallidurans and $S$. chlorophenolicum species (red circles). In this experimental setup, no $\mathrm{Hg}$ (II) ions were added. The initial cell density of each species was adjusted to be $\sim 10^{8}$ $\mathrm{CFU} \cdot \mathrm{mL}^{-1}$. Error bars indicate standard errors $(\mathrm{n}=2)$. 

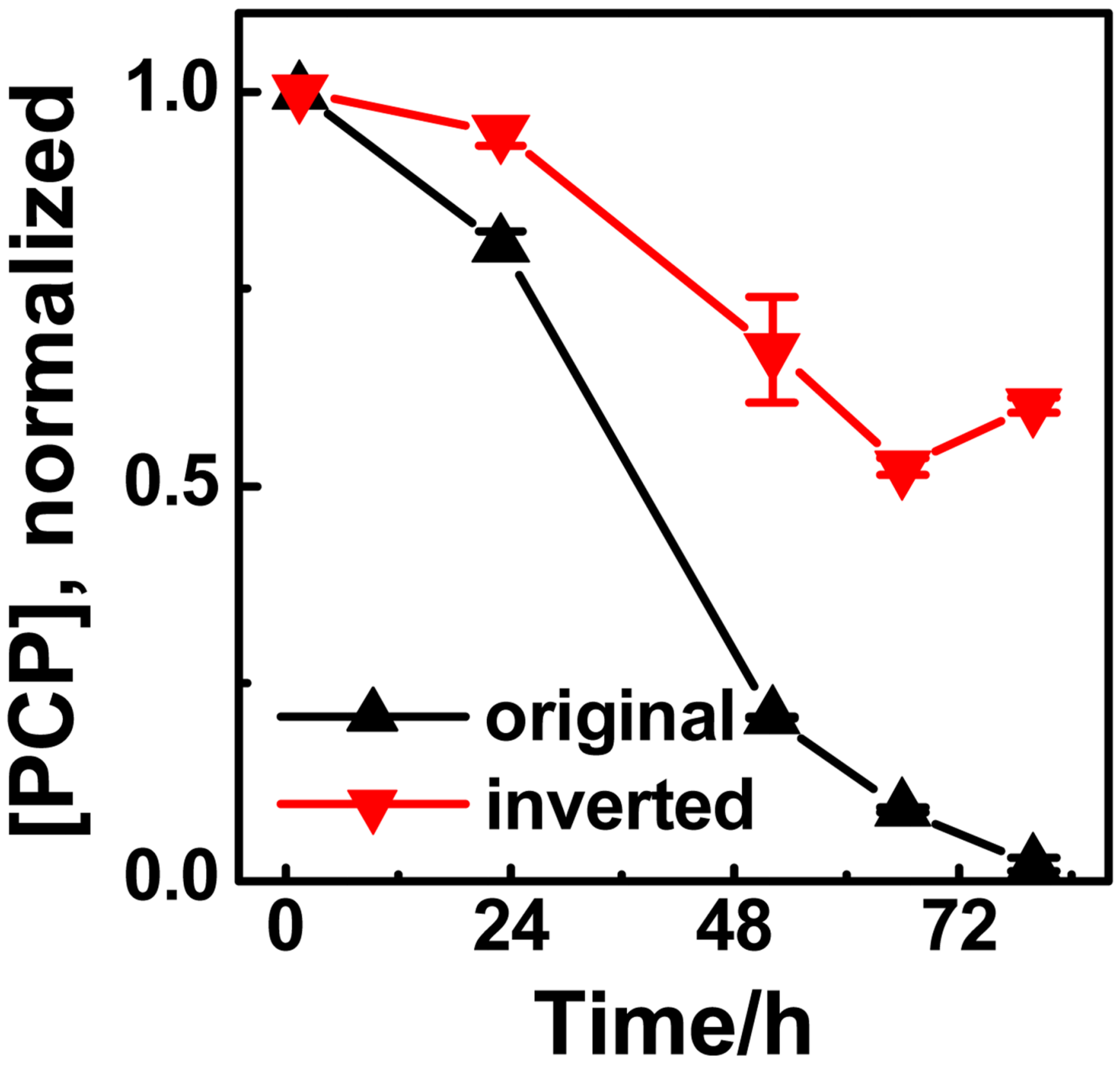

Figure 5.

Different spatial organizations affect the efficiency of the functions in a synthetic bacterial community. The experimental setup 'original' indicates a spatially structured fiber containing S. chlorophenolicum cells in the core layer and $R$. metallidurans cells in the shell layer (black triangles); in contrast, 'inverted' represents a structured fiber constraining $R$. metallidurans cells in the core layer and $S$. chlorophenolicum cells in the shell layer (red inverted triangles). In this experiment, initial concentration of $\mathrm{Hg}(\mathrm{II})$ was adjusted at 100 $\mu \mathrm{M}$ in $\mathrm{PM}$ media from $\mathrm{HgCl}_{2}$ stock solution $(10 \mathrm{mM})$. The final cell density of the species constrained in a core layer was $\sim 5 \times 10^{8} \mathrm{CFU} \cdot \mathrm{mL}^{-1}$, whereas the initial cell density of the species constrained in a shell layer was $\sim 8.33 \times 10^{7} \mathrm{CFU} \cdot \mathrm{mL}^{-1}$ at $0 \mathrm{~h}$. Error bars indicate standard errors $(n=2)$. 